\title{
IDENTIDADE CULTURAL E O SENTIMENTO DE PERTENCIMENTO
}

\author{
Gislene Angélica Conceição ${ }^{1}$
}

\begin{abstract}
Resumo: $O$ presente texto relata de forma ampla a experiência pedagógica desenvolvida com crianças de 4 até 10 anos, através de uma proposta educativa com enfoque no paradigma da transdisciplinaridade e complexidade e, de forma específica o projeto desenvolvido com um grupo de crianças do $3{ }^{\circ}$ ano do Ensino Fundamental 1, o qual teve como objetivo colaborar para a formação da identidade pessoal e social dos indivíduos envolvidos no processo, tendo a Cultura como sustentação desse trabalho. Como temática central para toda a escola foi utilizado o tema "Turismo para o Desenvolvimento Sustentável”, sendo esse sugerido pela UNESCO para o ano de 2017. Sem prescindir da ciência como forma de humanização e libertação, o projeto desenvolvido por cada grupo procurou construir algumas formas de religar o conhecimento balizado pelos pilares educacionais aprender a aprender, aprender a fazer, aprender a ser e aprender a conviver.
\end{abstract}

Palavras-chave: projeto, transdisciplinaridade, identidade cultural.

\section{CULTURAL IDENTITY AND THE BELONGING FEELING}

\begin{abstract}
The present text describes widely the pedagogical experience developed with children aged 4 to 10 years old, through an educational proposal that approaches the paradigm of transdisciplinarity and complexity and, specifically, the project developed with a group of $3^{\text {rd }}$ grade children, of which objective was collaborating for the formation of the personal and social identity of the individual involved in the process, having the Culture as a pillar for this project. The central thematic for the whole school was "Tourism for Sustainable Development", it being suggested by Unesco for the year of 2017. Considering Science as a way of humanization and freedom, the project developed by each group sought establish some ways of rejoin the knowledge based on educational pillars: learn how to learn, learn how to make, learn how to be and learn how to interact with others.
\end{abstract}

Keywords: project, transdisciplinarity, cultural identity.

1 Graduada em Pedagogia e Pós-Graduada em Psicopedagogia pela UNIVAP, especialização em Mediação: Intervenções Sistêmicas para Resolução de Conflitos e Disputas em Diferentes Contextos pela PUC - SP, Diretora e Sócio Mantenedora do Instituto Educacional e Cultural PAIDEIA. 


\section{INTRODUÇÃO}

Esta experiência educativa foi desenvolvida no Instituto Educacional e Cultural PAIDELA, uma escola da rede privada, localizada em Caraguatatuba, no litoral norte do Estado de São Paulo. Um município com uma população estimada pelo Instituto Brasileiro de Geografia e Estatística (IBGE) para o ano de 2017 de 116.768 pessoas. Escola membro do Programa de Escolas Associadas UNESCO (PEA-UNESCO) e certificada como Escola Criativa pela Rede Internacional de Escolas Criativas pela Universidade de Barcelona atende as modalidades Creche, Educação Infantil e Ensino Fundamental do $1^{\circ}$ ao $5^{\circ}$ ano.

A instituição carrega no próprio nome seu conceito educativo.

Seguindo a definição de Platão PAIDEIA é “(...) a essência de toda a verdadeira educação ou paideia é a que dá ao homem o desejo e a ânsia de se tornar um cidadão perfeito e o ensina a mandar e a obedecer, tendo a justiça como fundamento". (cit. in Jaeger, 1995: 147).

Sabemos que, diante da nossa realidade social esse tipo de desejo é quase utópico, mas segundo Boff (2016), a utopia pertence à realidade, porque esta não é feita apenas por aquilo que é dado, mas por aquilo que é potencial e que pode um dia se transformar em dado. A utopia nasce deste transfundo de virtualidades presentes na história, na sociedade e em cada pessoa.

Esta Unidade Escolar tem claro em sua Proposta Pedagógica seus alicerces filosóficos, sociológicos, metodológicos e psicológicos. Compreende que a criança não é um vir a ser, mas já é cidadã de direito, que tem voz e vez; por isso tem nesse espaço suas produções valorizadas e legitimadas.

Todas as propostas desenvolvidas visam o desenvolvimento integral do indivíduo partindo das suas possibilidades e ampliando suas potencialidades.

A esse respeito Dewey (1897) declara que, "A educação é um processo de vida e não uma preparação para a vida futura e a escola deve representar a vida presente - tão real e vital para o aluno como o que ele vive em casa, no bairro ou no pátio".

Então, diante das considerações sobre o processo de ensino e aprendizagem, como um processo de transformação sustentável, que a escola deve ser o lugar onde os estudantes possam criar vínculos afetivos com o meio em que vive para ir além do conteudismo, do utilitarismo imediato dos conhecimentos e, do individualismo, optamos em organizar nossa proposta através de Projetos, pois entendemos que esse tipo de organização de saberes possibilita as mais diferentes formas de expressão da compreensão de tudo que é trazido para os encontros e ainda levam em consideração qual tipo de contribuição emerge para promover a reflexão das possibilidades de transformação social.

Fernando Hernandéz (1998), entende o projeto como um ensejo onde os alunos percebem que o conhecimento não é exclusividade de determinada disciplina 
e, tem como objetivo fundamental a articulação dos conhecimentos, uma vez que rompe com essa forma rígida de enquadrar os conteúdos.

Esta forma de propor o processo educativo é reforçada por Torre e Zwierewicz (2009) os quais afirmam que o trabalho com projetos é uma proposta de ensino baseado nos interesse e necessidades de estudantes e professores, e que vão além do ensino fragmentado, gerando aprendizagens significativas para a vida.

Então, à luz do olhar do paradigma Ecossistêmico, que, para Moraes, é “[...] construído a partir de intercâmbios nutridores entre o sujeito e o objeto, mediante diálogos, interações, transformações e enriquecimentos mútuos [...]” (2004, p. 42-43) e, por priorizar a solidariedade, a inclusão e um ensino contextualizado, criamos condições para que o aprendizado acontecesse e siga acontecendo muito além da sala de aula, em diferentes espaços, com diferentes recursos, onde o professor atue como mediador, articulando as atividades desafiadoras favorecendo descobertas e cooperação, estimulando todas as faces da inteligência e aproveitando o conhecimento de cada um como ponto de partida para aquisição de novos conhecimentos para todo o grupo e de forma integrada com a cidade.

O que vai diferenciar esse Projeto de outros não organizados nesta linha metodológica é a preocupação existente em relacionar os três elementos definidos por (TORRE; ZWIEREWICZ, 2009) os quais são cognição, emoção e ação. Sendo que, a cognição será responsável pela construção de saberes, a emoção por tornar a aprendizagem significativa e relevante, a partir da dimensão emocional e, a ação relacionada a reconhecimento do eu considerando o outro, um chamamento à responsabilidade social como cidadão planetário.

É um ensino que segue a linha diálogo - ação - compreensão - participação, baseada em relações diretas das experiências dos estudantes, desenvolvendo assim capacidades de sentir, pensar e agir sobre si mesmo e sobre o mundo.

Foi elaborado um percurso de aprendizagem possível através de atividades que permeiam os diversos campos relacionados ao tema definido pela UNESCO para o ano de 2017 "Turismo Sustentável para o Desenvolvimento". Em mensagem de Irina Bokova, diretora-geral da UNESCO, ela enfatiza o motivo da definição do ano de 2017 como, Ano Internacional do Turismo Sustentável para o Desenvolvimento

\footnotetext{
“a importância do turismo internacional e, em particular, a designação de um ano internacional de turismo sustentável para o desenvolvimento, para promover uma melhor compreensão entre os povos em todo o mundo, levando a uma maior conscientização sobre o rico patrimônio das diversas civilizações”.(BUKOVA, 2017)
}

Unimos o tema, ao engajamento institucional pelas questões ambientais, sociais e turísticas, intimamente, ligadas com a localização geográfica do município de Caraguatatuba, buscando atender os objetivos de aprendizagens (ODS) previstos na agenda 2030 e, intencionando conscientizar e possibilitar práticas que contribuam para a formação de indivíduos conscientes de uma ética de pertencimento da espécie humana. 
Assim sendo, conscientes que o pensamento complexo é um paradigma emergente e, diante da urgência da construção desse cidadão com consciência planetária faz-se premente que no chão da escola, em nossa cotidianidade, de maneira prática, todavia sem determinismo reducionista, construir algumas formas de religar o conhecimento, através de uma proposta educativa transdisciplinar e criativa. Essa concepção contextualiza no mundo o objeto de conhecimento e o sujeito que aprende, auxiliando no sentimento de pertença a esse planeta.

A religação dos saberes nos leva a pensar no princípio hologramático, onde a parte está representada no todo e o todo tem cada uma de suas partes para além das competências individuais, mas como resultado que vai além, ou aquém, do que podem resolver juntas. (SUANNO, JH. 2017)

\section{DESENVOLVIMENTO}

A educação é parte fundamental para a transformação social, contudo para que isso ocorra faz-se condição sine qua non garantir a qualidade do processo educativo.

Para tanto levamos em consideração o parecer da UNESCO na ODS 4, da agenda 2030, a qual trata da Educação de qualidade, explicitando que devemos assegurar educação inclusiva e equitativa de qualidade, e promover oportunidades de aprendizagem ao longo da vida e para todos.

Assumimos o compromisso com o planeta e, de acordo com Paulo Freire,

"se o meu compromisso é realmente com o homem concreto, com a causa de sua humanização, de sua libertação, não posso por isso mesmo prescindir da ciência, nem da tecnologia, com as quais me vou instrumentando para melhor lutar por esta causa" (2007, p. 22).

Sendo assim, diante da importância que as normas e as representações sociais exercem sobre a formação do indivíduo, promovemos diferentes possibilidades de viver a cultura local, neste caso, especificamente do povo caiçara. Buscamos então, romper com os muros da escola e inseri-la na cidade e, com isso o inverso se fez real, ou seja, a cidade foi inserida na escola.

O desafio também envolveu conhecimento e exploração da cidade e da sua cultura, considerando o Turismo sob perspectiva de Gastal.

O Turismo é um campo de práticas histórico-sociais que pressupõem o deslocamento dos sujeitos em tempos e espaços diferentes daqueles dos seus cotidianos. É um deslocamento coberto de subjetividade, que possibilita afastamentos concretos e simbólicos do cotidiano, implicando, portanto, novas práticas e novos comportamentos diante da busca do prazer. (GASTAL, 2007, p. 11)

Apresentamos o projeto às instituições locais públicas, privadas e ONGs.

A fim de tornar possível um diálogo com a temática central com vistas ao trabalho com Projeto voltado à formação pessoal, institucional e social partimos 
dos conhecimentos prévios individuais e coletivos, e fizemos um levantamento de quais os saberes estavam imbricados no tema principal. Em seguida, foram estabelecidas as primeiras ligações entre o município e as temáticas mundiais.

Mapa conceitual 1 - Relações entre a temática mundial e o município

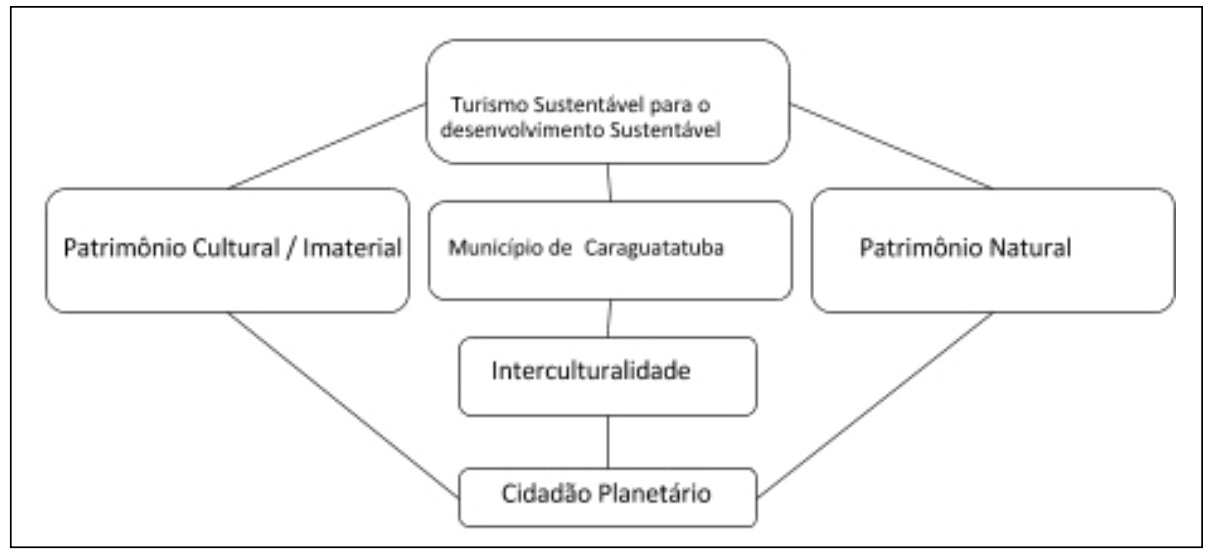

Iniciamos o trabalho de projetação (projetar a ação) do percurso lembrando da necessidade também da qualificação dos educadores, afinal o exercício da docência impõe ao educador a seriedade da sua formação.

Era momento de saber quais os conhecimentos prévios do grupo e partir para a ampliação dos horizontes conceituais. Nos momentos de formação em serviço vivenciamos muitas leituras, pesquisas, vídeos e discussões para ligar e religar os conhecimentos específicos das diversas áreas ao tema central.

Saindo do senso comum revisitamos o sentido de turismo e o papel do turista, para assim pensar nas próximas conexões possíveis.

Mais uma vez quem nos auxiliou nessa seara foram as autoras Gastal e Moesch (2007), as quais sugerem em sua concepção que,

o indivíduo pode usufruir dos mesmos benefícios associados a viagens de lazer em seu próprio território, desde que consigam desenvolver um processo de estranhamento, perceber locais e costumes já conhecidos sob novas perspectivas, imbuindo do olhar de um estrangeiro em sua própria cidade e assim estabelecendo novas relações com os espaços.

Traçamos uma nova teia de possibilidades considerando como orientações didáticas os seguintes pontos:

- Promover uma prática de reflexão sobre os sentidos e as práticas de preservação;

- Promover atitudes de solidariedade, respeito ao meio ambiente, a si e aos outros, bem como o horror a qualquer forma de preconceito e desrespeito aos direitos humanos; 
Então, em um trabalho coletivo e colaborativo a proposta foi tomando corpo. Ao ligar e religar assuntos relevantes ao desenvolvimento dos conhecimentos conceituais, procedimentais e atitudinais surgiam outras tantas possibilidades de aprendizagens, ampliando assim o universo cultural e científico tanto de estudantes como dos profissionais envolvidos, auxiliando na construção e aprimoramento do sentimento de pertencimento dos indivíduos na comunidade e do respeito às diversidades culturais.

Mapa conceitual 2 - Conteúdos possíveis de serem interligados em todos os anos escolares.

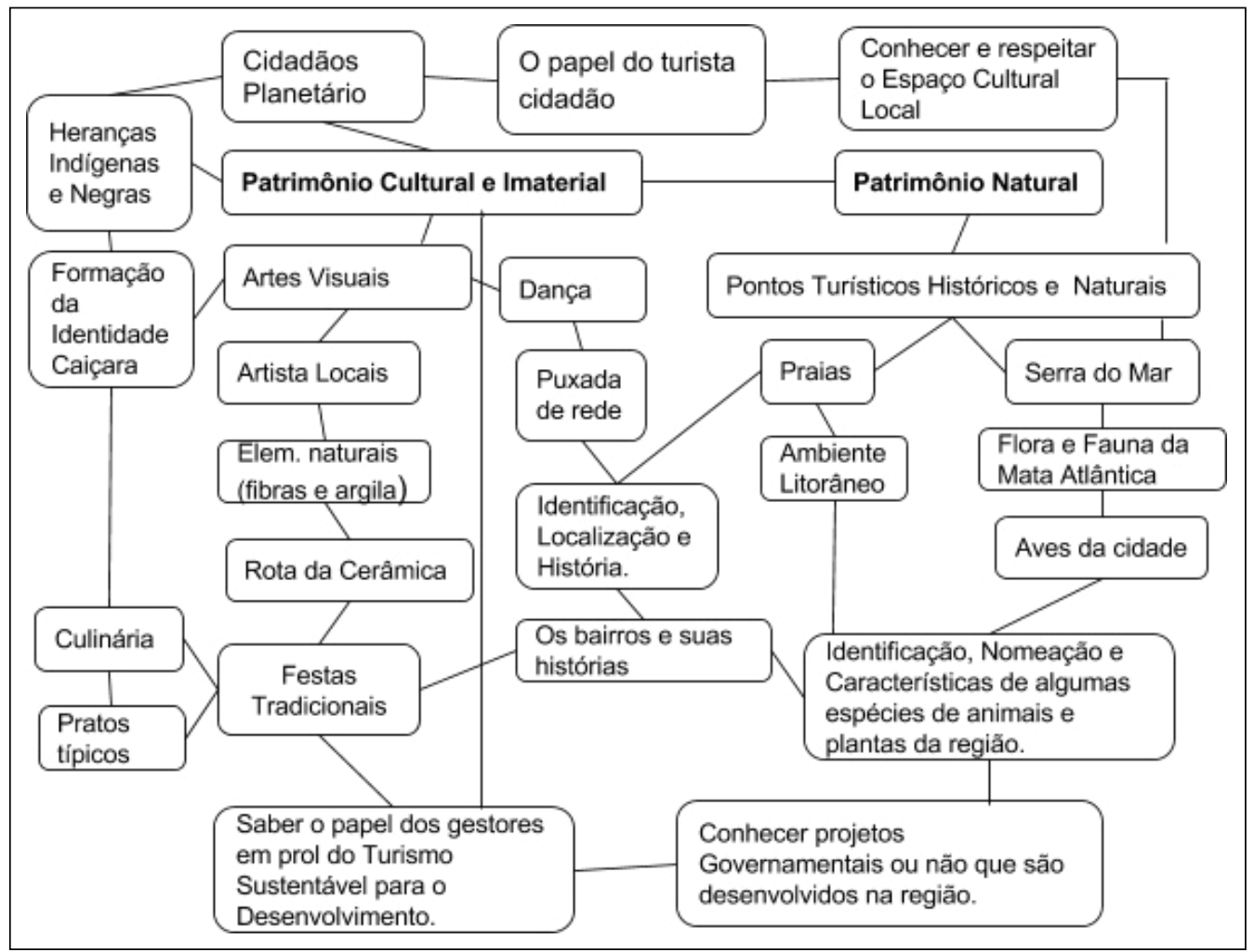

Estava assim desenhada a rota mestra para as aprendizagens de forma a ultrapassar os limites impostos por uma ou outra disciplina.

A única certeza que tínhamos era que, embora o percurso estivesse desenhado, a partir dos estudos, outros assuntos de interesse poderiam ser trazidos tanto pelos alunos como pelos educadores.

Foi lançado o convite para revisitar a cidade e sua história, procurando promover nos indivíduos uma total dedicação nos momentos de encontros com esse estudo. Vale ressaltar que, embora tivéssemos o olhar sobre o tema principal, o assunto para cada grupo não foi escolhido a esmo, foram levadas em consideração 
o interesse das crianças e as orientações dos documentos norteadores da educação brasileira para cada modalidade de ensino.

No Segmento da Educação Infantil foram definidos como temas:

- "Os pássaros que nos visitam" para o grupo de crianças de 3 anos

- "Pelas praias de Caraguatatuba" - para o grupo de crianças de 4 anos

- "Para além das Praias" - para o grupo de crianças de 5 anos

No Ensino Fundamental de 1॰ ao 5॰ anos:

- "Turista cidadão"

- "Conheça sua cidade - por ruas e bairros de Caraguatatuba"

- "Nossa cidade tem história"

- "Gestão pública"

O trabalho envolveu conhecimentos do âmbito Identidade e Autonomia, bem como do campo das Línguas Portuguesa e Inglesa, escritas e faladas; das Ciências Naturais e Sociais, das Artes Visuais, da Dança, da Música, da Literatura, da Culinária e em alguns casos específicos, também da Matemática.

Dentre todos os Projetos relataremos nesta publicação apenas um deles, o projeto "Nossa cidade tem História". Esse foi desenvolvido com um grupo de 19 crianças, do $3^{\circ}$ ano do Ensino Fundamental 1, da Professora Daiane Miriam dos Santos, com o apoio da Coordenadora Ana Amélia de Oliveira Faria.

Patrimônio Natural e Cultural é o conteúdo principal desse trabalho. Aproveitamos que já faz parte dos conhecimentos propostos aos estudantes deste ano de escolaridade para alinhá-lo ao tema proposto pela UNESCO, assim o religamos aos diversos assuntos possibilitando uma aprendizagem mais ampla e significativa.

Em nosso caso específico, não se trata de um assunto totalmente novo, visto que a Proposta Pedagógica da escola favorece, desde a Educação Infantil, a vivência de experiências de aprendizagens relacionadas ao município e suas riquezas culturais e naturais.

Uma das principais razões da preservação do patrimônio é a melhoria da qualidade de vida da comunidade e também um incentivo ao exercício da cidadania. Pois, quando se conhece mais a comunidade e toda sua história se abre caminhos para entender mais sobre a cultura, e também a necessidade de a preservar. abaixo.

O desenvolvimento da proposta se deu a partir do percurso de possibilidades 
Mapa Conceitual 3 - Conteúdos a serem tratados no grupo do 3o ano.

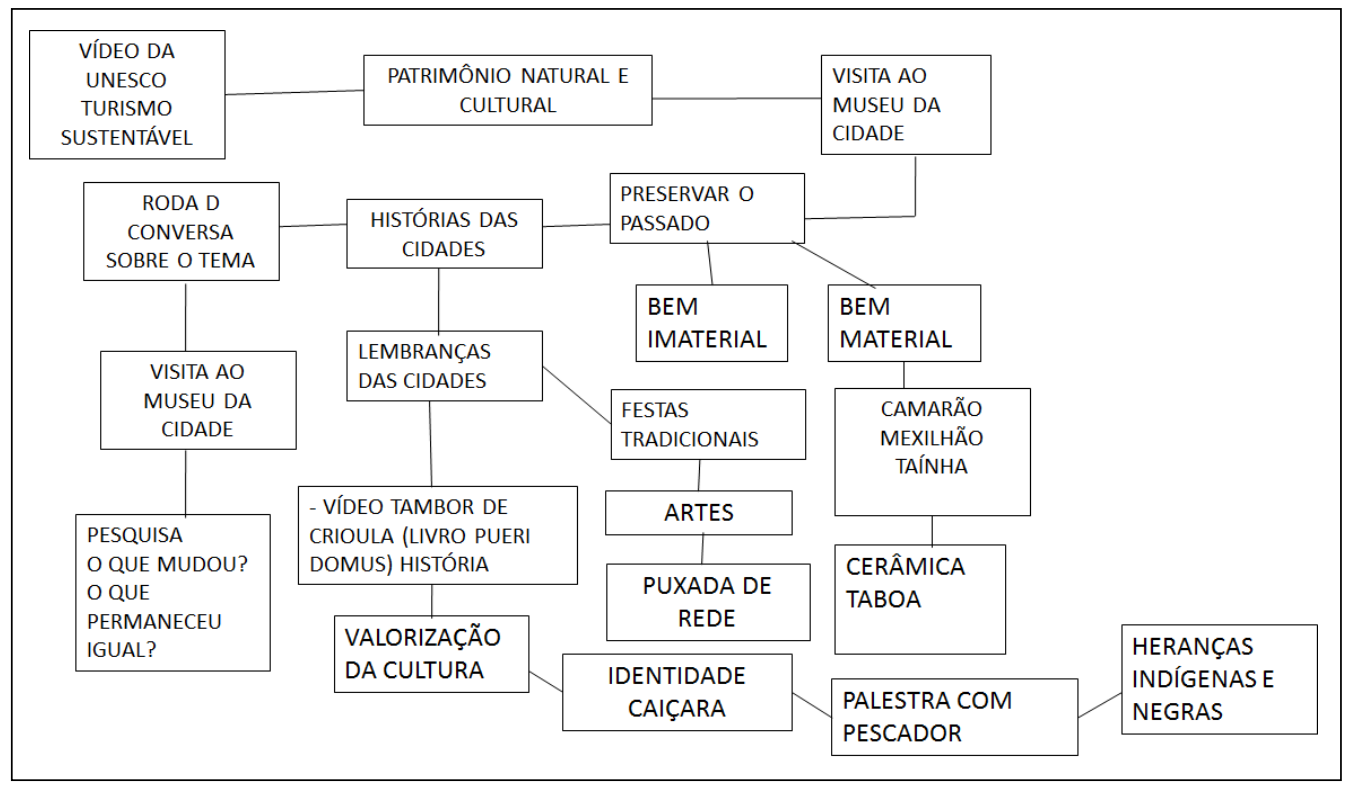

\section{Epítome ou ponto de partida}

Era chegado o momento de despertar interesses e olhares mais atentos em estudantes, família e comunidade. Afinal, a valorização do processo educativo se dá a partir do momento em que se torna claro para os responsáveis a intencionalidade e profundidade daquilo que está sendo tratado, ao mesmo tempo que compreendem o percurso a ser trilhado.

Assim sendo, para obter a atenção de todos foram feitos lançamentos simultâneos do Projeto.

No monitor de TV situado na recepção da escola colocamos para passar, diariamente, dois vídeos liberados pela UNESCO acerca do Turismo Sustentável; "Ano Internacional do Turismo Sustentável para o Desenvolvimento 2017", com 00:01:58 de duração e outro relacionado a Campanha Passaporte Verde do Governo Federal do Brasil, intitulado "Passaporte Verde - Turismo Sustentável por um Planeta Vivo", com duração de 00:03:56.

Todas as famílias receberam um informativo da escola sobre o projeto anual contendo um convite para embarcarem conosco nesta viagem e fazer parte das descobertas sobre Caraguatatuba e anexados dois folders. 
Fotografia dos folders anexados

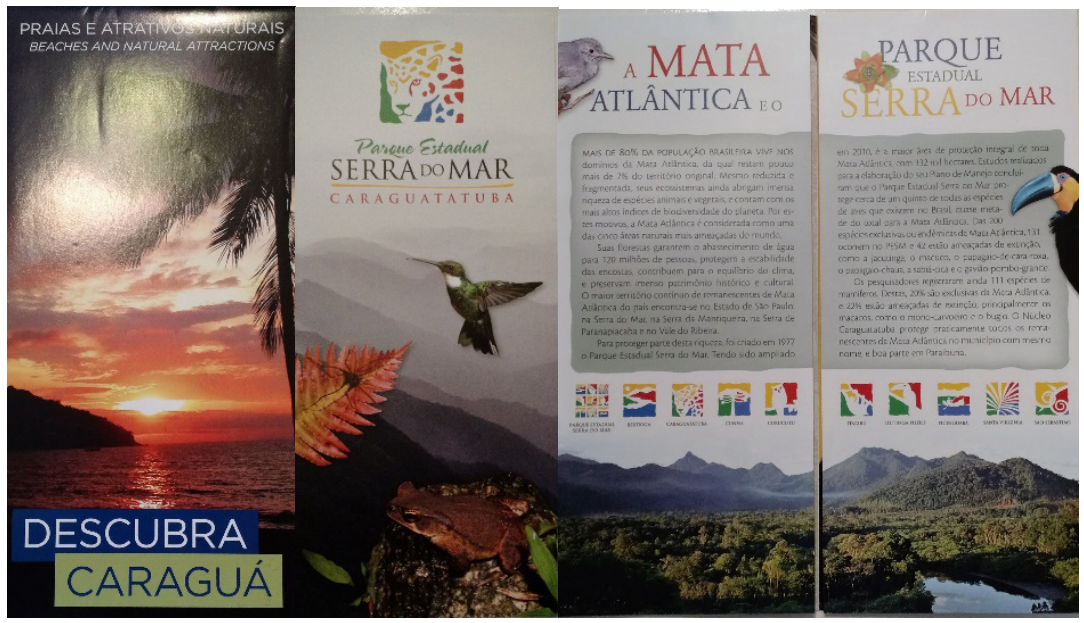

As crianças foram convidadas a assistir os dois vídeos citados. Após a sessão de vídeo foi realizada uma roda de conversa com o objetivo de possibilitar o levantamento de conhecimentos prévios individuais e coletivos, dúvidas e interesses.

Enquanto os lançamentos aconteciam em sala eram fixadas nas paredes do pátio da escola 13 banners de fotografias (cedidos pela Secretaria Municipal de Turismo de Caraguatatuba), medindo cada um aproximadamente $100 \mathrm{~cm} \times 120 \mathrm{~cm}$, de pontos turísticos ou imagens da tradição cultural do Caiçara.

A ideia era chamar a atenção das crianças e das famílias para a Nossa Cidade, história e cultura caiçara.

\section{Legitimação Teórica e Pragmática:}

Através do questionamento lançado aos estudantes: “_E agora? Como fazer para saber o que não sabemos?”, foi possível conduzi-los à reflexão das ações necessárias sobre o aprender a aprender.

Em função da escola ter em sua prática ações de ocupação dos espaços públicos da cidade e realizar trabalhos de campo frequentemente, algumas sugestões aconteceram no mesmo instante.

“_Ah! É fácil! Através de pesquisas, leituras, vídeos e trabalhos de campo”.

Sim, mas quais as vivências são possíveis para aprender a história da cidade e entender sobre o Patrimônio Cultural?

- "Vamos ao Museu".

- "Poderemos fazer pesquisas na internet também".

• "Assistir vídeos."

• "Têm livros sobre a cidade. Poderemos ler e pesquisar neles também". 
Quando se aposta na criança como sujeito produtor de conhecimento nenhuma das propostas são descartadas.

Foram acrescentadas outras atividades que contribuem para o desenvolvimento de diferentes habilidades nos estudantes como, leitura, interpretação, entrecruzamento de informações, conceituação e extrapolação. Entre elas leituras de textos informativos (material apostilado utilizado como apoio) sobre Patrimônio Cultural, leitura de livros de Contos e Causos do folclore municipal, sobre a história da cidade e referentes à Puxada de rede e ao Tambor de Crioula. Também assistiram vídeos relacionados a esses dois últimos temas.

A partir das diversas possibilidades de vivências que tiveram os estudantes foram se familiarizando com a temática, entendendo e, portanto, respeitando cada dia mais a diversidade cultural. Tudo ia fazendo mais sentido, ia se tornando mais bonito o encontro com o outro e consigo mesmo.

Estratégias como as rodas de conversas, rodas de história com contadores profissionais, debates, entrevistas com munícipes, produções gráficas textual e artística, aulas de Capoeira e os trabalhos de campo favoreceram o aprimoramento do olhar e da sensibilidade.

Entre perguntas, respostas e pareceres sobre o que vinham vivenciando e, sem se intimidar com a convencionalidade, mostravam suas reflexões e seus conhecimentos provisórios acerca do tema, os quais mobilizavam novas pesquisas e novas discussões.

- "O que é sustentabilidade?” (grupo)

• "Sustentável é preservar algo.” (grupo)

• "É a relação do homem com o meio onde vive.” P.F.O. (9 anos)

- "É cuidado com a cidade, com a vida de cada pessoa." M.R.M.A. (8anos e 7 meses)

- "É a relação das histórias com a vida que cada um quer mostrar para o turista." M.V.S.G. (8 anos e 6 meses)

- "Por que queremos preservar se muitos não conhecem a história da nossa cidade?" V.A.C. (9 anos e 1 mês)

- "A igreja, a praça e os locais da cidade contam a história, mas como fazer para que o turista se interesse por eles?” B.B.C. ( 9 anos e 1 mês)

\section{Objetivos:}

- Identificar e diferenciar elementos naturais e culturais que podem constituir a paisagem;

- Diferenciar fenômenos sociais, culturais e naturais.

- Perceber a intensidade, o ritmo e as causas das suas transformações;

- Identificar e registrar patrimônios históricos já constituídos. 
- Comparar as diferenças e semelhanças entre os hábitos do caiçara antigamente e hoje em dia.

- Compreender a importância da preservação dos patrimônios para a história de um povo;

- Valorizar a pluralidade do patrimônio sociocultural brasileiro;

- Entender a importância do papel da cultura para o alcance da sustentabilidade;

- Compreender historicamente formas de participação social e política;

- Utilizar diversas linguagens para expressar sua compreensão sobre os estudos.

- Compreender o sentido da sustentabilidade para a vida no planeta.

- Entender que a educação pode ajudar a criar um mundo mais sustentável, equitativo e pacífico;

- Perceber que pequenas ações contribuem para um melhor desenvolvimento sustentável da cidade e por isso do planeta;

- Tornar-se protagonista do ato de cognição, mas também do comentário, posto que o aprendizado deve ser acompanhado de reflexão e revisitação.

- Vivenciar o aprendizado com prática, não tanto para buscar um fim, mas para mudar a si mesmo.

- Expressar a dimensão estética como qualidade essencial do aprender, do conhecer e do relacionar.

\section{Itinerário}

A etapa seguinte ao lançamento foi composta da visita ao MACC - Museu de Arte de Caraguatatuba. Tiveram uma visita monitorada e vivenciaram uma roda de conversa com os personagens Nhá Rita e Neco Borba contadores de causos. Depois elaboraram um registro gráfico textual das observações e das experiências desse trabalho de campo. 
Fotografia 1 - Crianças no MACC em observação.

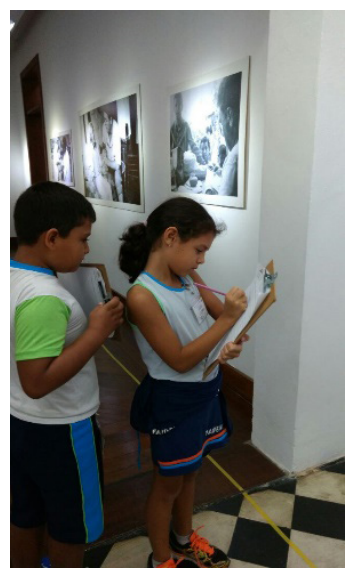

Fotografia 2 - Grupo do 3o ano em roda de conversa com os personagens Nhá Rita e Neco Borba.

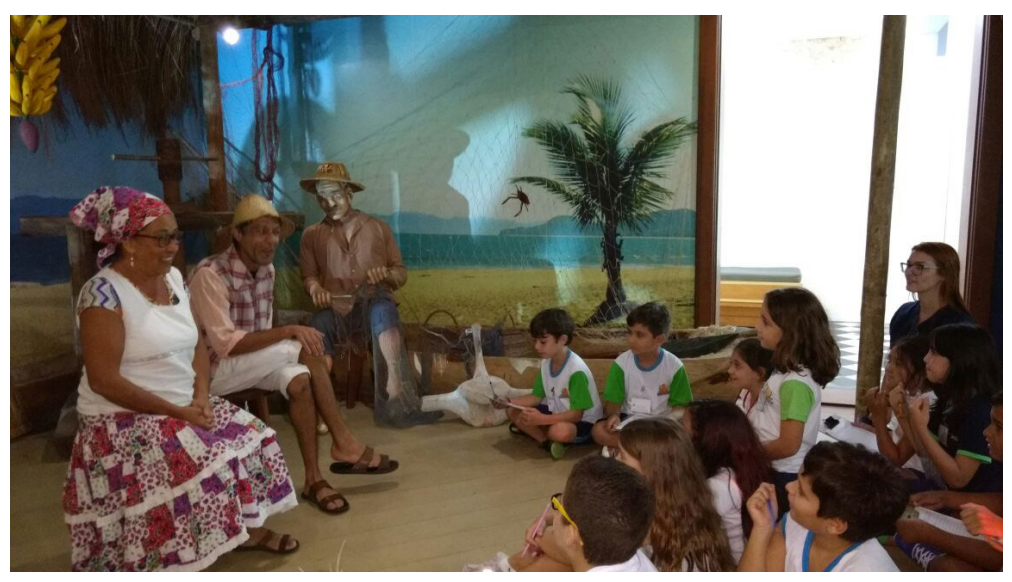

De volta à escola compartilharam entre eles suas anotações e, posteriormente, definiram individualmente, qual o questionamento gostariam de ter respondido. Com o olhar focado nas heranças indígenas quiseram saber sobre a tribo dos Gueromimis, que habitava a região, sobre a fundação da cidade e sobre a Puxada de rede como prática dos Pescadores.

Durante a visita ao Museu se depararam com um número significativo de obras sobre a história do município, suas lendas e causos, contada em versos e prosa. Encontraram um tipo diferente de texto, o cordel e observaram ser de um único autor, Maurício Poeta Neto, que se tornou conhecido dos leitores ao dedicarse inicialmente, à pesquisa, coleta, e recriação de lendas e mitos de Caraguatatuba. Com isso, entraram em contato com várias obras do Cordelista. 
Propusemos às crianças a possibilidade de conhecer pessoalmente o autor. Ficaram entusiasmados. Fizemos um convite formal para ele conhecer o Projeto. Pessoalmente, explicamos a proposta e agendamos uma entrevista dele com as crianças. Previamente, em sala de aula, os estudantes pensaram, discutiram e elaboraram as perguntas a serem feitas ao escritor.

Fotografia 1- Maurício Poeta Neto no hall da escola.

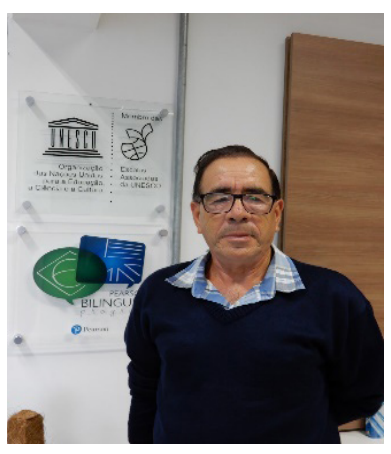

Fotografia 2- O mesmo autor em momento de autógrafo após entrevista.

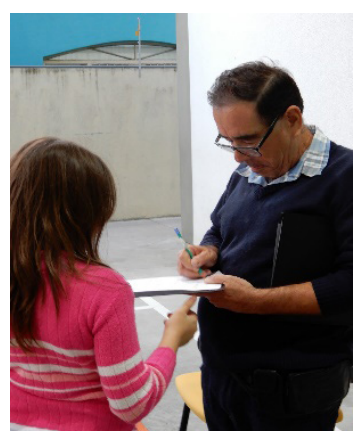

Depois que compreenderam que o autor utilizava o esquema em septilhas, isto é, deixar alguns versos soltos e alguns com rimas específicas, como recurso de produção dos seus textos, as crianças construíram, coletivamente, produziram o primeiro cordel e, através desse gênero literário representaram um aspecto do modo de vida caiçara.

$$
\begin{gathered}
\text { O caiçara sincero, } \\
\text { ama nadar e pescar, } \\
\text { com seu jeito caprichoso, } \\
\text { utiliza das águas tirar, } \\
\text { um pouquinho da história, } \\
\text { revelada na memória, } \\
\text { de uma vida a desvendar. }
\end{gathered}
$$


Seu sotaque é diferente, ele vive sempre no mar, cultivando seu alimento, e também sai pra pescar, com muita paciência, ele ganha experiência e volta para o lar.

Posteriormente, foram autores do seu próprio cordel, incluindo a capa da publicação. Para fazer a capa utilizaram o recurso da isogravura, uma técnica para fazer xilogravura usando isopor. Pratos de isopor foram reciclados para esse trabalho. Ao propor esta produção compreenderam como os cordéis são publicados, ao mesmo tempo que refletiram sobre resíduos sólidos e a relação com a sustentabilidade.

Fotografias 1 e 2 - Aluna em momento de criação e confecção da gravura sobre seu cordel.
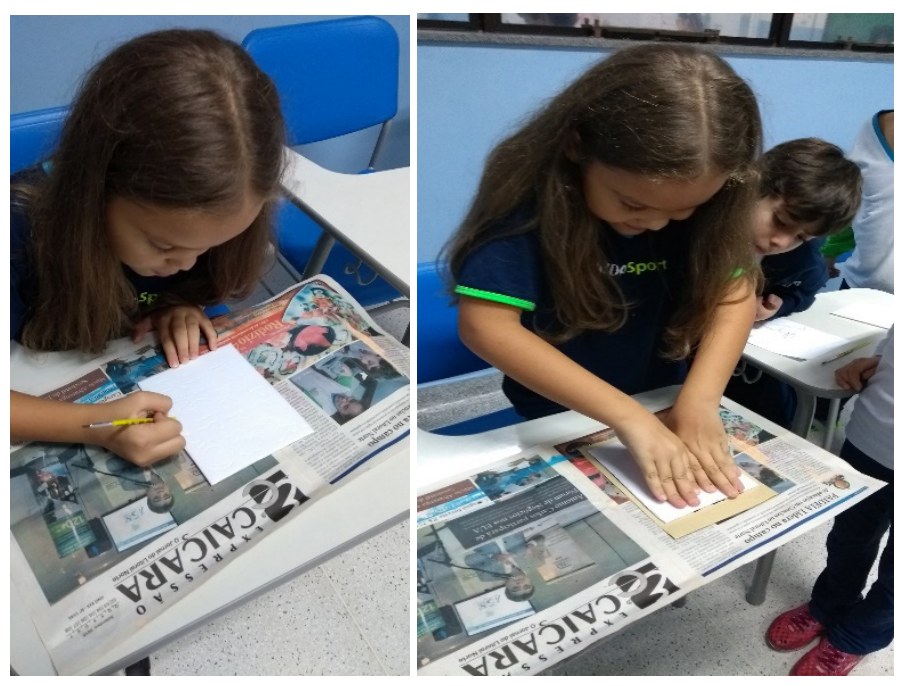
Fotografia 3 - Trabalho impresso de uma das crianças desse grupo.

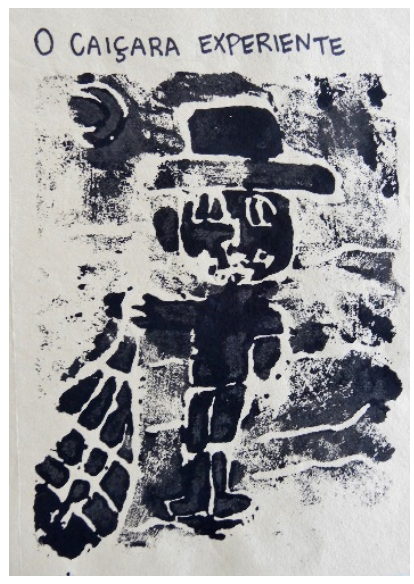

Fotografia 4 - Cordel de autoria de um dos estudantes do mesmo grupo.

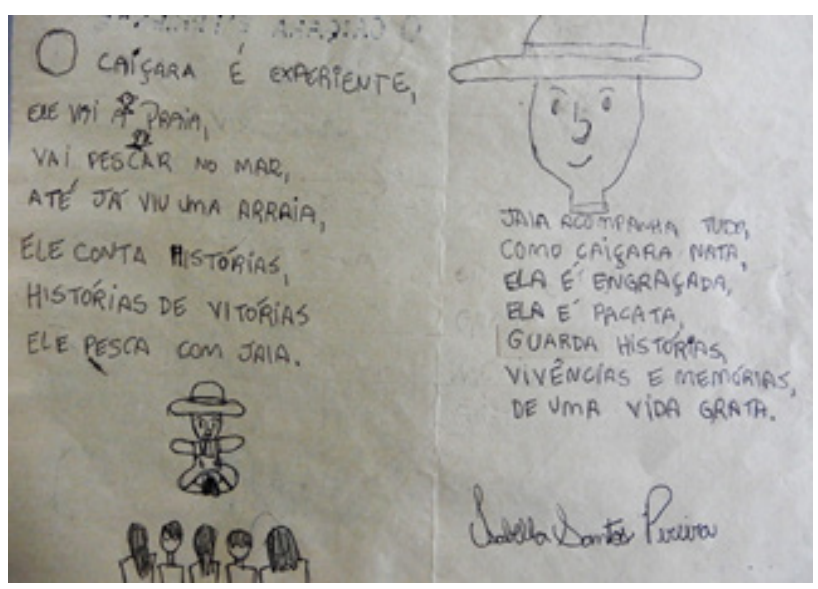

Os encontros entre a comunidade e educandos dentro e fora da escola contribuíram para a reflexão de todo o grupo sobre o sentido de pertencimento e com isso de responsabilidade social.

As Festas Populares da Tainha e do Camarão, que aconteceram no município durante o desenvolvimento do projeto, tiveram outro sabor. Ganharam um novo olhar das crianças e seus familiares dando ainda mais sentido a tudo que estava sendo pesquisado e conversado.

Os registros variados sucediam aos encontros coletivos, fossem esses dentro ou fora da escola.

A puxada de rede, outro foco de interesse das crianças, foi vivenciada através das aulas de Capoeira, as quais ocorriam, semanalmente, com uma especialista. Nessas, trabalharam alguns aspectos da cultura africana e a Puxada de rede como 
manifestação cultural, já que esta trata da memória e vivência de um povo que encontrou na pesca uma forma de sobrevivência.

Os registros variados sucediam os encontros coletivos, fossem esses dentro ou fora da escola.

No percurso de descobertas sobre as Artes foi possibilitado às crianças conhecerem obras produzidas por um artista local a partir de fibras de palmeiras. Acrescentado a essa experiência promovemos o contato com a modelagem. Esta última experiência foi vivida no ateliê da artista Vânia Takahashi, que faz parte do grupo de artistas que pertencem a Rota da Cerâmica, criada para mapear e divulgar os ateliês de cerâmica dos artistas plásticos da cidade. Sentir e expressar era a tarefa principal.

Mais um entrevistado em nosso percurso, um pescador local. Como temática para a conversa surgiram Costumes e Festas tradicionais. Depois, dificuldades da vida moderna - o ontem, o hoje e o amanhã e os cuidados com o meio ambiente natural e social.

Para alinhavar os conhecimentos e estruturar todos os conceitos, fatos e princípios abordados e desenvolvidos durante o projeto foi realizada uma retrospectiva de forma coletiva. Assim também fortalecemos o arraigamento das atitudes promotoras para o desenvolvimento de um mundo sustentável.

A produção de cartões postais sobre a cidade fecha esta etapa de descobertas e encantos sobre uma parte de nossa história, demonstrando nosso respeito e desejo de termos respeitadas e valorizadas a pluralidade cultural.

\section{Polinizaçáo:}

\section{Encontro de Leitores}

Sob o tema "Patrimônio do Povo Caiçara - Natureza e Cultura", o encontro promoveu a mostra das primeiras produções literárias infantis do ano, juntamente com outras formas de expressão como a dança e as artes visuais. Instalação, Limeriques, Cordel, Contos e causos, produções individuais e coletivas chamaram a atenção de todos.

Ao buscarmos apoio de diversos setores da sociedade partilhávamos o projeto, nossas metas e sonhos com os concidadãos revigorando o olhar sobre a necessidade de uma cidade educativa. Com isso, tivemos o apoio do setor público municipal representado pela a Secretaria Municipal de Turismo e da FUNDACC (Fundação Cultural de Caraguatatuba) contribuindo com: cessão de fotos relacionadas aos pontos turísticos e o modo de vida caiçara, elementos da cultura como canoas, redes, cestos entre outros, com fotografias antigas de personagens da história, com o boneco gigante (Zé Caiçara), bem como com orientações do Diretor de Folclore e Diretor de Arte para montagem do evento. 
O Parque Estadual da Serra do Mar colaborou com a doação de folders e vídeos.

O terceiro setor também participou através da Associação de Maricultores, o qual contribuiu com elementos do cultivo do marisco na região e quadros ilustrativos desse processo.

Buscamos também um representante da arte natural, aquela que utiliza elementos da natureza na sua produção, o Artista Plástico Alfeo Croce contribuiu para a mostra de obras produzidas a partir das fibras de palmeiras.

As famílias participaram como colaboradoras e não apenas como visitantes. Colaboraram com elementos da cultura para ambientação da escola e com a declamação de um trecho de um dos Cordéis de autoria de Maurício Poeta Neto.

A dramatização da Puxada de rede ficou a cargo dos estudantes do $3^{\circ}$ ano.

Fotografia: Alunos do 3o ano realizando a apresentação da Puxada de rede no Encontro de Leitores.

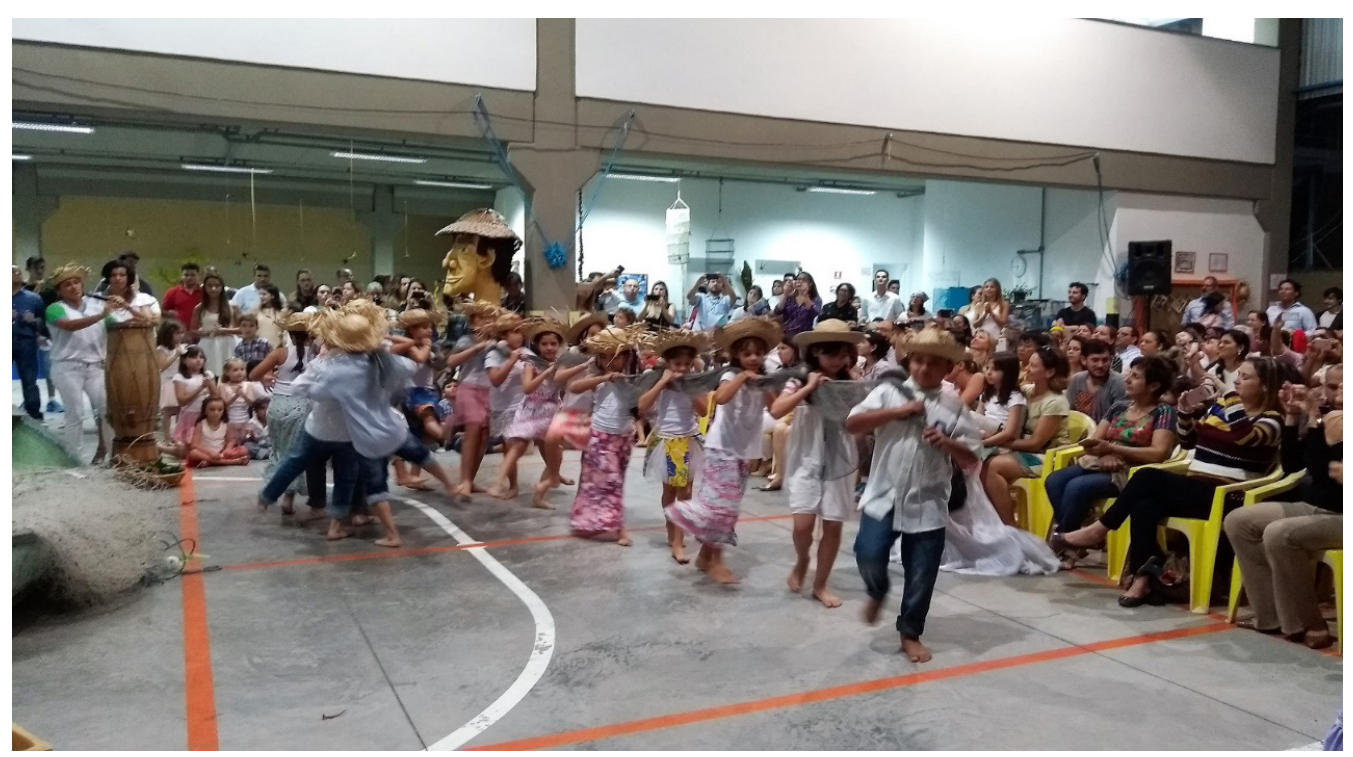

Recebemos para a abertura do evento os contadores de história municipal os quais nos reuniu numa grande roda de história, resgatando a tradição humana milenar.

Diante dos seus trabalhos, as crianças compartilhavam de forma orgulhosa e empoderada os saberes construídos com as experiências. 
Fotografia - Alunas do 30 ano diante de seus trabalhos durante a Mostra no Encontro de Leitores.

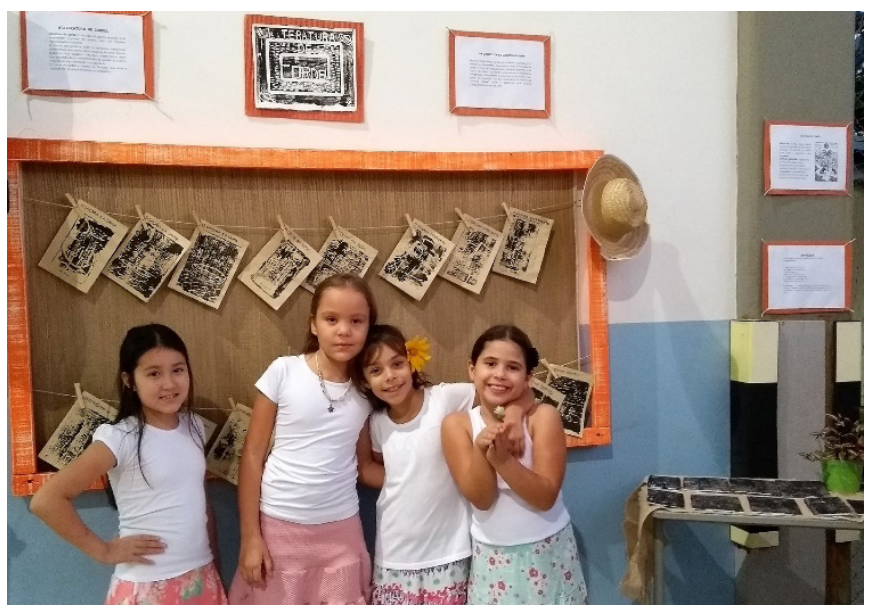

\section{Dia da Família na Escola e Mostra Cultural}

Anualmente, propomos o encontro das famílias no espaço escolar. Nesse dia procuramos possibilitar a vivência dessas nas práticas educativas adotadas por essa escola, para que desta maneira possam compreender todas as competências e habilidades mobilizadas durante uma proposta de atividade delineada pela complexidade e transdisciplinaridade.

A fim de estabelecer relação com o tema do projeto anual e inspirar novas reflexões escolhemos a temática Humanidades para esses dois eventos.

Tal escolha se deu devido às reflexões sobre o que nos faz verdadeiramente humano, isto é, aquilo que nos diferencia de outros animais. A partir desse momento foram concebidos novos subtemas de pesquisa sem perder o vínculo com o que as crianças já vinham elucubrando.

Esse grupo seguiu tratando sobre a Cultura, afinal o Homem se caracteriza a partir de diferentes e diversas dimensões, sendo talvez a cultura uma das mais amplas e complexas para o entendimento.

Segundo, Carneiro (2009) o homem transcende, transforma, se autoproduz e cria novo significado e novas formas de aproveitamento já existentes. O Homem se humaniza produzindo seu mundo, gerando sua marca cultural ou as diferentes manifestações culturais.

Como elemento cultural a professora elegeu as lendas, as quais sempre serviram como forma de ensinamento.

Segundo a Professora Daiane M. Santos, “...toda história traz conhecimento, e como consequência desta aquisição a relação entre o gênero textual e a comunicação se tornam importantes etapas para o desenvolvimento do ser humano." 
O contexto vivenciado apresentou a cultura de diferentes povos, por meio de lendas que retratam características e expressões vividas por antepassados. Estas expressões provocaram no leitor, também co-produtor das atividades, um sentido maior para o que há de humano em si.

Para o dia do encontro ficou definido que as famílias desse grupo iriam trabalhar com a lenda "A mulher que virou Urutau". Tínhamos um protocolo composto de 11 passos para o desenvolvimento da atividade, o qual deveria ser desenvolvido por adultos e crianças juntos, lendo, interpretando e representando através da linguagem da modelagem o texto compartilhado. Ao final. cada grupo teria sua obra representativa da lenda.

Fotografia 1 -Famílias reunidas em subgrupos realizando leitura coletiva

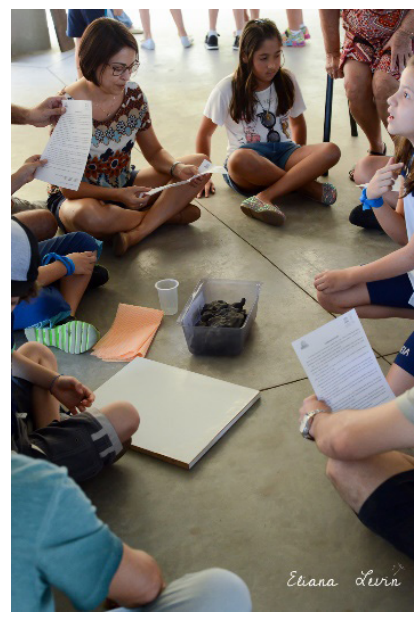

Fotografia 2 - Famílias reunidas decidindo sobre como representar a lenda.

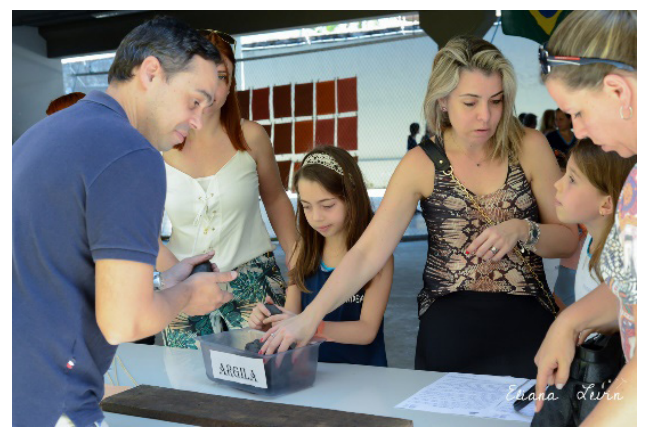


Fotografia 3 - Mãos de adulto e criança em produção coletiva.

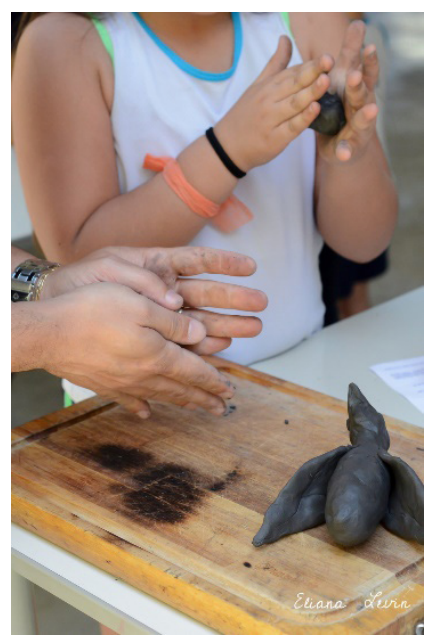

\title{
CONCLUSÁO
}

Nesses 9 anos de existência, o Instituto Educacional e Cultural PAIDEIA vem quebrando paradigmas e comprovando através de ações educativas concretas que, quando as crianças são protagonistas de sua aprendizagem e, quando os conhecimentos são ligados tudo faz sentido, o mundo se conecta.

Assumindo uma postura pedagógica que pressupõe educar para a vida real, as crianças desenvolvem competências e habilidades, atitudes e valores que os tornam estudantes responsáveis, críticos, criativos, mas principalmente, felizes, confiantes e motivados, sempre. Aprendendo sobre nós mesmos nos compreendemos como humanos.

Ao partilhar com a sociedade esse modelo educativo e ocupando os espaços públicos favorecemos o repensar coletivo sobre a urgência de uma formação de um indivíduo com visão holística e a compreensão de que, não estamos sós, mas respiramos a mesma atmosfera que todos os seres viventes.

O trabalho com projetos permitiu o nosso aprimoramento como seres humanos e suscitou novas possibilidades de projetos transdisciplinares.

A professora, Daiane Miriam dos Santos se descobre e inspirada, conclui seu trabalho com uma produção autoral.

\author{
"No Paideia, \\ o saber é diverso \\ e o turismo sustentável \\ é conhecimento imerso \\ dos diversos momentos \\ vivências e embasamentos
}


em um simples verso.

Versos que indicam,

Patrimônio Cultural

de um povo caiçara,

material ou imaterial

da construção de um saber

baseado no compreender

da identidade cultural.

De um conjunto,

de ideias e informações,

trocas de vivências

e surgimento de opiniões,

de aluno para aluno,

mediante o oportuno

momento de realizações".

\section{REFERÊNCIAS}

A UNESCO e o Ano Internacional do Turismo Sustentável - 2017. Disponível em: <http://www.unesco.org/new/pt/brasilia/about-this-office/prizes-andcelebrations/2017-international-year-of-sustainable-tourism/> . Acesso em: 25 mar. 2017.

BOFF, Leonardo - O resgate da utopia no contexto atual - 11/03/2016. Disponível em: <https://leonardoboff.wordpress.com/2016/03/11/o-resgate-da-utopia-no-contextoatual/>. Acesso em: 24 out. 2017. BRASIL. Ministério Das Relações Exteriores. Objetivos de Desenvolvimento Sustentável. 112/02/2016 - Disponível em: <http:// www.itamaraty.gov.br/images/ed_desenvsust/ODSportugues12fev2016.pdf $>$. Acesso em: 25 mar. 2017.

Caderno Virtual de Turismo. ISSN: 1677-6976 Vol. 8, N 3 (2008) Turismo, políticas públicas e cidadania GASTAL, S. \& MOESCH, M. São Paulo: Aleph, 2007. Disponível em: <www.ivt.coppe.ufrj.br/caderno/index.php/caderno/article/download/366/230>. Acesso em: 10 mar. 2017.

CARNEIRO, Neri - Uma antropologia da cultura III: Cultura: a criação humana - 2009. Disponível em: < http://www.webartigos.com/artigos/uma-antropologia-da-cultura-iiicultura-a-criacao-humana/13430/>. Acesso em: 23 out 2017. 
Conceito de Paidéia. Disponível em: <www.educ.fc.ul.pt/docentes/opombo/hfe/ momentos/escola/paideia/conceitodepaideia.htm>. Acesso em: 26 out 2017

FREIRE, P. Pedagogia da Autonomia: saberes necessários à prática educativa. 35 eds. São Paulo: Paz e Terra, 2007. (Coleção Leitura)

HERNANDEZ, F. Transgressão e mudança na educação: Projetos de trabalho. Porto Alegre: ArtMed, 1998.

MAGALHÃES, R. N. Antologia Poética.Caraguatatuba, SP: FUNDACC, 2010.

MORIN, E. Os sete saberes necessários à educação do futuro.8. ed. São Paulo: Cortez, Brasília: UNESCO,2004.

MARROU, Henri-Irénée. História da Educação na Antiguidade

NETO, M. P. A tromba d'água. Caraguatatuba, Caraguá Artes Gráficas.

. Antonio Benetazzo, um bravo militante. Caraguatatuba, FUNDACC, 2013.

. Cordelzinho Cirandeiro. Curitiba: do autor, 2011.

. Caraguá e bairros di-versos. Caraguatatuba, FUNDACC.

Pedagogia de Projetos: Contribuições para Uma Educação Transformadora. Disponível em: <http://www.pedagogia.com.br/artigos/pedegogiadeprojetos/index.php?pagina=1> Acesso em: 24 out. 2017.

Portal do Governo Brasileiro. Disponível em: < https://cidades.ibge.gov.br/brasil/sp/ caraguatatuba/panorama>. Acesso em: 10 out 2017.

SUANNO, J. H. - Por que uma escola criativa? pg. 83 Ciudadania Planetária

TORRE, S. de la e ZWIEREWICZ, M. (Coords) Uma Escola para o Século XXI: Escolas criativas e resiliência na educação. Florianópolis: Insular, 2009.

TORRE, S. de la; PUJOL, M.A.; SILVA, V.L.de S. (Coords) Inovando na Sala de Aula: Instituições Transformadoras. Blumenau: Nova Letra, 2013.

VELASCO, Juan M. G. (Coord.) Ciudadanía Planetaria, (pag. 11. Pensamiento religado y condición humana) Bolivia, 2017.

VELASCO, Juan M. G. Religaje Educativo: Espacio - Tiempo, Bolívia.

ZABALA, A. A Prática educativa: como ensinar. Porto Alegre: ArtMed, 1998. 